\title{
Perbandingan Peta Gempa pada Analisis Potensi Likuefaksi (Studi Kasus Jalan Tol Ruas Probolinggo - Banyuwangi Seksi II)
}

\author{
AHMAD FAISAL AMRI, IKHYA \\ Program Studi Teknik Sipil, Institut Teknologi Nasional Bandung \\ Email: faisalamri0221@gmail.com
}

\begin{abstract}
ABSTRAK
Probolinggo Jawa timur memiliki sesar yang berpotensi akan terjadinya gempa. Sesar Probolinggo bergerak sebesar 0,2 mm per tahun. Pasir lepas yang terdapat pada jalan tol Probolinggo - Banyuwangi ini sebagai salah satu indikasi potensi likuefaksi. Analasis potensi likuefaksi menggunakan metode Seed et al (1985). Analisis potensi likuefaksi pada tanah ini menggunakan beberapa peta gempa dan variasi fines content pada tanah. Perbedaan percepatan gempa dan fines content pada beberapa peta gempa tersebut akan menunjukan pengaruh pada potensi terjadinya likuefaksi pada tanah. Hasil penelitian tanah dengan kandung fines content 35 \% terjadi likuefaksi lebih sedikit dibanding tanah dengan kandungan fines content yang lebih kecil. Hal tersebut terjadi karena nilai fines content berpengaruh pada hasil CRR. Peta gempa dengan periode ulang lebih besar memiliki percepatan gempa besar sehinnga terjadi titik likuefaksi lebih banyak dibanding peta gempa dengan periode ulang lebih kecil. Hal tersebut terjadi karena percepatan gempa berpengaruh pada nilai CSR.
\end{abstract}

Kata kunci: CSR, CRR, fines content, likuefaksi, percepatan gempa

\begin{abstract}
Probolinggo, East Java has a fault that has the potential to cause an earthquake. The Probolinggo Fault moves by $0.2 \mathrm{~mm}$ per year. The loose sand found on the Probolinggo - Banyuwangi toll road is an indication of the potential for liquidation. Analysis of the potential for liquefaction using the method of Seed et al (1985). Analysis of the potential for liquefaction on this land using several earthquake maps and variations in soil content. The difference in earthquake acceleration and fines content on some earthquake maps will show the effect on the potential occurrence of liquefaction on the ground. The results of soil research with 35\% fines content have fewer liquefaction compared to soil with smaller fines content. This happens because the value of fines content affects the CRR results. Earthquake maps with greater return periods have large earthquake acceleration so that there are more liquefaction points than earthquake maps with smaller return periods. This happens because the earthquake acceleration affects the value of CSR.
\end{abstract}

Keywords: CSR, CRR, fines content, liquefaction, earthquake acceleration 


\section{PENDAHULUAN}

Berdasarkan buku Peta Sumber Bahaya Gempa Indonesia 2017 di daerah Probolinggo Jawa timur memiliki sesar yang berpotensi terjadinya gempa. Sesar Probolinggo bergerak sebesar $0,2 \mathrm{~mm}$ per tahun. Potensi gempa yang terjadi pada sesar Probolinggo akan berpengaruh terhadap potensi likuefaksi tanah di daerah tersebut. Gempa yang disebabkan sesar Probolinggo ini akan memberikan beban dinamis pada tanah, hal tersebut akan menjadi pemicu terjadinya likuefaksi pada tanah. Tanah yang terlikuefaksi akan kehilangan daya dukungnya dan bersifat seperti air, hal ini sangat berbahaya jika di atas tanah tersebut terdapat infrastuktur seperti jalan tol, gedung dan juga bangunan infrastuktur lainnya.

Penyelidikan tanah yang dilakukan pada proyek tol Probolinggo - Banyuwangi ini, hasil pengujian standart peneteration test (SPT) di beberapa titik pada tol tersebut memiliki kandungan pasir lepas dengan nilai N-SPT kecil, serta muka air tanah yang tinggi. Pasir lepas tersebut merupakan salah satu indikasi potensi likuefaksi, nilai N-SPT yang kecil pula mengindikasikan pasir lepas tersebut memiliki potensi likuefaksi.

Untuk hal itu penelitian ini membahas permasalahan analisis potensi terjadinya likuefaksi yang dipengaruhi oleh gempa. Percepatan gempa berubah setiap tahunnya, hal ini bisa berakibat berbeda pada tanah yang berpotensi likuefaksi tersebut. Analisis potensi likuefaksi pada tanah ini menggunakan beberapa peta gempa dan variasi fines content pada tanah. Perbedaan percepatan gempa dan fines content pada analisis tersebut akan menunjukan pengaruh pada potensi terjadinya likuefaksi di tanah. Analasis potensi likuefaksi menggunakan metode Seed, et al. (1985), hasil analisis akan menunjukan tanah pada tol Probolinggo - Banyuwangi tersebut berpotensi mengalami likuefaksi atau tidak.

\section{TINJAUAN PUSTAKA}

\subsection{Likuefaksi}

Umumnya, jenis tanah yang rentan terhadap likuefaksi adalah pasir lepas yang muka air tanahnya tidak jauh dari permukaan. Saat terjadi gempa, penyebaran dari gelombang geser menyebabkan kontraksi antar partikel pasir, sehingga terjadi peningkatan tekanan air pori. Peningkatan nilai air pori yang diakibatkan oleh getaran permukaan dan pergerakan aliran air ke atas ini menyebabkan tanah pasir berada pada kondisi cair, yang disebut juga sebagai likuefaksi (Day, R. W., 2001). Menurut Ishihara, K. (1985) likuefaksi ini terjadi ketika nilai tegangan efektif sama dengan nol dan partikel tanah menjadi lepas, seakan partikel-partikel ini mengapung di atas air.

\subsection{Faktor-faktor Penyebab Likuefaksi}

Banyak faktor yang menyebabkan likuefaksi berdasarkan uji laboratorium dan studi lapangan (Day, R. W., 2001). Diantaranya adalah sebagai berikut:

(a) intensitas dan durasi gempa bumi;

(b) muka air tanah;

(c) jenis tanah;

(d) kepadatan relatif awal;

(e) gradasi dan analisis butiran tanah;

(f) kondisi drainase dan dimensi deposit atau endapan;

(g) confining pressures. 


\subsection{Metode Analisis Likuefaksi (Seed, et al., 1985)}

Metode yang paling umum digunakan adalah analisis potensi likuefaksi menggunakan Standard Peneteration Test (SPT) yang dikemukakan oleh Seed, et al. (1985). Berikut adalah langkah analisis potensi likuefaksi:

\section{Cyclic Stress Ratio (CSR)}

Cyclic Stress Ratio (CSR), likuefaksi pada tanah pasir jenuh diakibat oleh adanya Cyclic Stress Ratio (CSR). Besaran CSR dipengaruhi oleh percepatan gempa maksimum batuan dasar, tegangan tanah total, tegangan tanah efektif, dan reduksi faktor kedalaman. Seed, et al. (1985) mengembangkan metode dengan membandingkan rasio tegangan siklik akibat gempa bumi atau CSR. Nilai CSR dapat dihitung menggunakan Persamaan 1.

$$
\frac{\tau_{a v}}{\sigma_{v}^{\prime}}=0,65 \cdot \frac{\alpha_{\max }}{g} \cdot \frac{\sigma_{v}}{\sigma_{v}^{\prime}} \cdot r_{d}
$$

halmana:

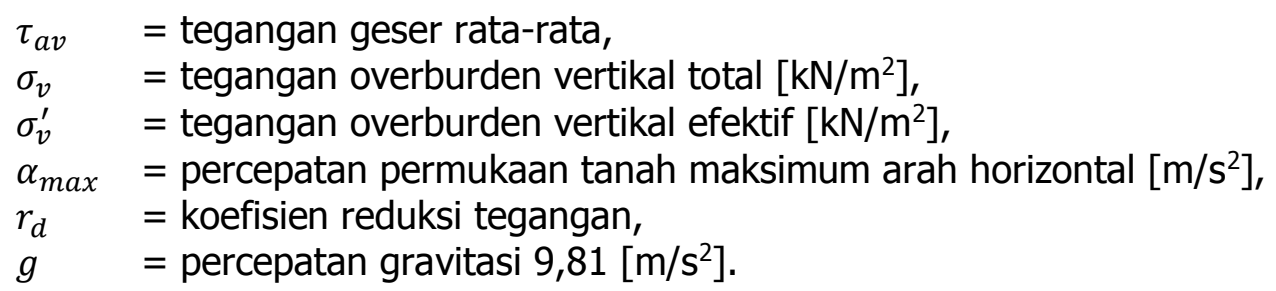

Untuk memperhitungkan koefisien reduksi tegangan, Liao, S. S. C. \& Whitman, R. V. (1986) mengembangkan persamaan untuk mengestimasi reduksi tegangan. Besarnya koefisien reduksi tegangan dapat dihitung berdasarkaan Persamaan 2 hingga Persamaan 5 atau menggunakan grafik hubungan antara koefisien reduksi tegangan dengan kedalaman seperti pada Gambar 1.

$$
\begin{gathered}
r_{d}=1,0-0,00756 z \text { untuk } z \leq 9,15 \mathrm{~m} \\
r_{d}=1,174-0,0267 z \text { untuk } 9,15 \mathrm{~m}<z \leq 23 \mathrm{~m} \\
r_{d}=0,774-0,008 z \text { untuk } 23 \mathrm{~m}<z \leq 30 \mathrm{~m} \\
r_{d}=0,5 \text { untuk } z>30 \mathrm{~m}
\end{gathered}
$$

halmana:

$z=$ kedalaman lapisan pasir $(0-20 \mathrm{~m})$.

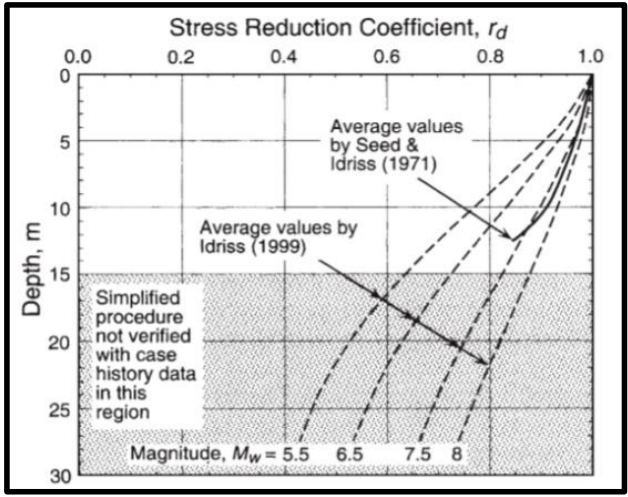

Gambar 1. Grafik stress reduction coefficient vs depth

(Sumber: Seed, H. B. \& Idriss, I. M., 1970)

RekaRacana: Jurnal Teknik Sipil - 66 


\section{Cyclic Resistance Ratio (CRR)}

Kemampuan tanah untuk menahan likuefaksi atau Cyclic Resistance Ratio (CRR) dapat ditentukan berdasarkan data hasil uji Standard Peneteration Test(SPT). Nilai CRR bergantung dari data hasil uji seperti hasil SPT karena pada umumnya berkorelasi dengan parameter in situ, seperti jumlah pukulan SPT.

Jika nilai tahanan tanah terhadap likuefaksi atau Cyclic Resistance Ratio (CRR) lebih besar dari pembebanan yang terjadi atau Cyclic Stress Ratio (CSR) maka tanah aman dari likuefaksi. Namun apabila nilai CRR lebih kecil dari CSR maka tanah tidak aman dari likuefaksi.

Berdasarkan nilai uji N-SPT uji lapangan Seed, et al. (1985) menyimpulkan ada tiga perkiraan potensial likuefaksi yang dapat diidentifikasi, dapat dilihat pada Tabel 1.

\section{Tabel 1. Potensi Likuefaksi Berdasarkan N-SPT}

\begin{tabular}{cc}
\hline$\left(\boldsymbol{N}_{\mathbf{1}}\right)_{60}$ & Potential Damage \\
\hline $0-20$ & High \\
\hline $20-30$ & Intermediate \\
\hline$>30$ & No significant damage \\
\hline
\end{tabular}

(Sumber: Seed, et al., 1985)

Untuk mencari nilai $N_{60}$ koreksi untuk hasil pengujian dapat menggunakan Persamaan 6.

$$
N_{60}=N_{m} \cdot \frac{E R_{m}}{60}
$$

Besaran energi rasio $\left(E R_{m}\right)$ untuk nilai N-SPT dapat dilihat Tabel 2.

Tabel 2. Energi Rasio

\begin{tabular}{ccccc}
\hline Country & $\begin{array}{c}\text { Hammer } \\
\text { Type }\end{array}$ & Hammer Release & $\begin{array}{c}\text { Estimated Rod } \\
\text { Energy } \\
{[\%]}\end{array}$ & $\begin{array}{c}\text { Correction Factor for } \\
\mathbf{6 0 \%} \text { Rod Energy }\end{array}$ \\
\cline { 2 - 5 } Japan & Donut & Free-fall & 78 & $78 / 60=1,3$ \\
\cline { 2 - 5 } & Donut & $\begin{array}{c}\text { Rope and pulley with } \\
\text { special throw release }\end{array}$ & 67 & $67 / 60=1,12$ \\
\hline \multirow{2}{*}{ United State } & Safety & Rope and pulley & 60 & $60 / 60=1$ \\
\cline { 2 - 5 } Argentina & Donut & Rope and pulley & 45 & $45 / 60=0,75$ \\
\hline \multirow{2}{*}{ China } & Donut & Rope and pulley & 45 & $45 / 60=0,75$ \\
\cline { 2 - 5 } & Donut & Free-fall & 60 & $60 / 60=1$ \\
\cline { 2 - 5 } & Donut & Rope and pulley & 50 & $50 / 60=0,83$
\end{tabular}

(Sumber: Seed, et al., 1985)

Nilai $N_{60}$ dikoreksi dengan tegangan overburden dengan menggunakan Persamaan 7.

$$
\left(N_{1}\right)_{60}=C_{N} \cdot N_{60}
$$

Nilai faktor koreksi untuk tegangan overburden $\left(C_{N}\right)$ menggunakan Persamaan 8 (Liao, S. S. C. \& Whitman, R. V., 1986) berikut.

$$
C_{N}=\sqrt{\frac{100}{\sigma_{v}^{\prime}}}
$$


Setelah mengetahui nilai $\left(N_{1}\right)_{60}$ selanjutnya adalah menentukan besaran fines content pada tanah. Menurut Ishihara, K. (1985) jenis tanah yang rentan terhadap likuefaksi adalah sebagai berikut:

(a) tanah nonplastis (nonkohesif) tanah nonkohesi yang rentan terhadap likuefaksi adalah pasir bersih (clean sands);

(b) pasir berlumpur nonplastis (nonplastic silty sands);

(c) lumpur nonplastis (nonplastic silt) dan kerikil (gravel).

Berdasarkan Youd, T. L. \& Gilstrap, S. D. (1999) agar tanah kohesi dapat terlikuefaksi maka tanah tersebut harus memiliki karakteristik di bawah ini:

(a) tanah memiliki ukuran partikel yang lebih kecil daripada 0,005 $\mathrm{mm}$ sebanyak kurang dari 15 persen dari total partikel kering;

(b) tanah memiliki batas cair kurang 35;

(c) kadar air harus 0,9 kali lebih besar daripada batas cair.

Setelah mengetahui besaran nilai fines content selanjutnya menentukan nilai cyclic resistance ratio (CRR) untuk gempa berkekuatan 7,5 Mw dengan menggunakan grafik pada Gambar 2.

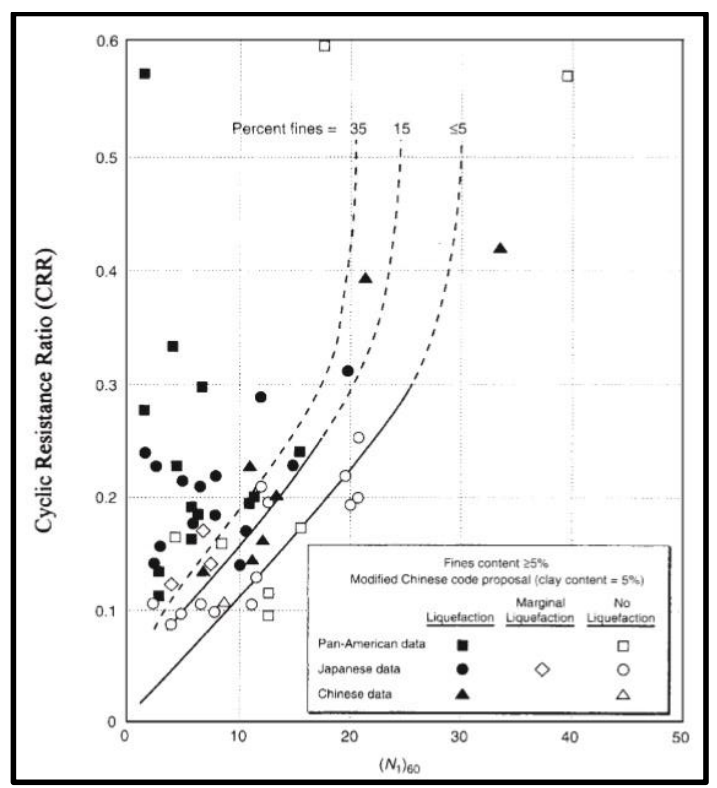

Gambar 2. Grafik cyclic resistance ratio for clean and silty sands for $M 7,5$ earthquakes (Sumber: Seed, et al., 1985)

Jika besar magnitude gempa tidak sama dengan 7,5 Mw maka menggunakan koreksi untuk magnitude gempa lain dengan Tabel 3. untuk mengetahui besaran magnitude scaling factor (MSF) selanjutnya nilai CRR dihitung menggunakan Persamaan 9.

Tabel 3. Magnitude Scaling Factor (MSF)

\begin{tabular}{cc} 
Anticipated Earthquake Magnitude & Magnitude Scaling Factor (MSF) \\
\hline $81 / 2$ & 0,89 \\
\hline $71 / 2$ & 1,00 \\
$63 / 4$ & 1,13 \\
6 & 1,32 \\
\hline $51 / 4$ & 1,50 \\
\hline
\end{tabular}

(Sumber: Seed, et al., 1985)

$$
C R R=M S F \cdot C R R_{7,5}
$$

RekaRacana: Jurnal Teknik Sipil - 68 
halmana:

$M S F=$ magnitude scaling factor,

$C R R_{7,5}=$ cyclic resistance ratio 7,5 Mw.

\section{METODOLOGI PENELITIAN}

Untuk memberikan gambaran yang jelas mengenai tahapan kegiatan penelitian yang dilakukan, maka dapat dilihat bagan alir penelitian pada Gambar $\mathbf{3}$ berikut.

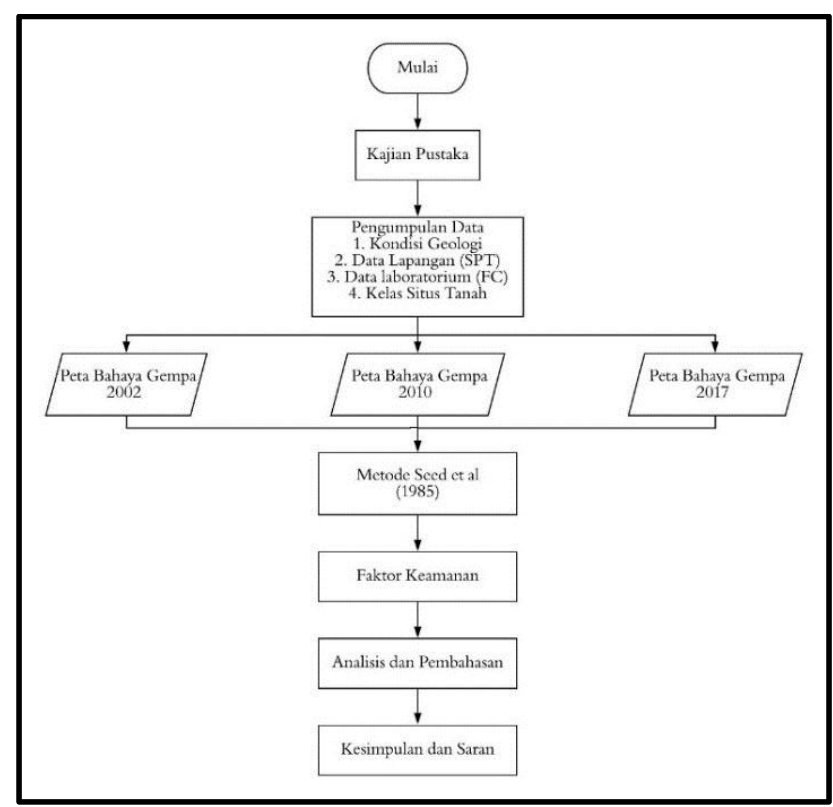

Gambar 3. Bagan alir penelitian

\section{ANALISIS DAN PEMBAHASAN}

\subsection{Likuefaksi Analisis Potensi Likuefaksi Metode Seed, et al. (1985)}

Dalam menganalisis potensi likuefaksi menggunakan metode Seed, et al. (1985) berdasarkan data uji Standard Penetration Test (SPT). Evaluasi potensi likuefaksi berdasarkan nilai Cyclic Stress Ratio (CSR) dan nilai Cyclic Resistance Ratio (CRR). Tahapan dalam analisis likuefaksi dengan metode Seed, et al. (1985) dapat dilihat pada Gambar 4.

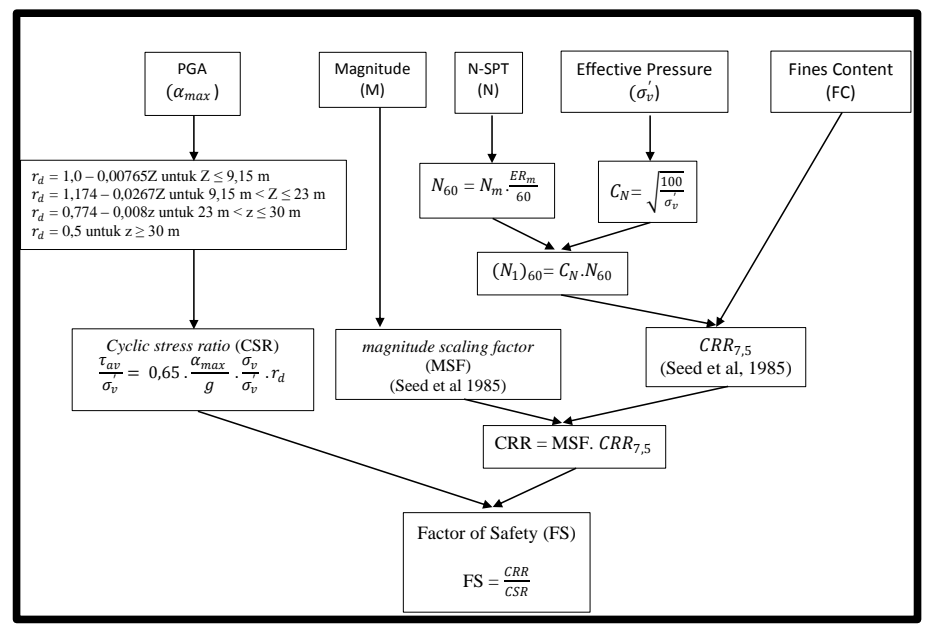

Gambar 4. Bagan alir analisis likuefaksi

(Sumber: Seed, et al., 1985)

RekaRacana: Jurnal Teknik Sipil - 69 
Jika besar magnitude gempa tidak sama dengan 7,5 Mw maka menggunakan koreksi untuk magnitude gempa lain dengan Tabel 4. untuk mengetahui besaran magnitude scaling factor (MSF) selanjutnya nilai CRR dihitung menggunakan Persamaan 9.

Tabel 4. Kombinasi Analisis Likuefaksi

\begin{tabular}{ccccc}
\hline Bore Log & $\begin{array}{c}\text { Peta Gempa } \\
\text { Periode Ulang } \\
\text { [tahun] }\end{array}$ & $\begin{array}{c}\text { Kelas Situs } \\
\text { Tanah }\end{array}$ & $\begin{array}{c}\text { Fines Content } \\
{[\%]}\end{array}$ \\
\hline \multirow{3}{*}{10} & 2002 & 500 & Soft Soil & 0 \\
\cline { 2 - 5 } & 2010 & 1.000 & Medium Soil & 15 \\
\cline { 2 - 5 } & 2017 & 2.500 & & 35 \\
\hline
\end{tabular}

(Sumber: Seed, et al., 1985)

\subsection{Percepatan Puncak Batuan Dasar (PGA)}

Analisis likuefaksi dilakukan menggunakan tiga peta bahaya gempa, yaitu peta bahaya gempa 2002, 2010 dan 2017. Periode ulang yang digunakan dalam analisis berdasarakan SNI 8640:2017 dengan peruntukan infrastruktur non-gedung yaitu percepatan puncak batuan dasar untuk probabilitas terlampaui $2 \%$ dalam 50 tahun atau periode ulang 2.500 tahun. Dalam analisis digunakan percepatan puncak batuan dasar untuk probabilitas terlampaui $10 \%$ dalam 50 tahun atau periode ulang 500 tahun dan percepatan puncak batuan dasar untuk probabilitas terlampaui $10 \%$ dalam 100 tahun atau periode ulang 1.000 tahun. Percepatan puncak batuan dasar $(P G A)$ seluruh periode ulang di wilayang Probolinggo dapat dilihat pada Tabel 5.

Tabel 5. Percepatan Puncak Batuan Dasar Probolinggo

\begin{tabular}{cccc}
\hline $\begin{array}{c}\text { Periode Ulang } \\
\text { [tahun] }\end{array}$ & $\begin{array}{c}\text { Peta } \\
\mathbf{2 0 0 2}\end{array}$ & $\begin{array}{c}\text { Peta } \\
\mathbf{2 0 1 0}\end{array}$ & $\begin{array}{c}\text { Peta } \\
\mathbf{2 0 1 7}\end{array}$ \\
\hline 500 & 0,15 & 0,175 & 0,2 \\
\hline 1.000 & - & 0,25 & 0,3 \\
\hline 2.500 & - & 0,3 & 0,4 \\
\hline
\end{tabular}

Berdasarkan hasil pengujian Standard Penetration Test(SPT) di lapangan didapat hasil tanah tergolong dalam dua kalsifikasi situs tanah, yaitu soft soil dan medium soil. Penentuan klasifikasi situs tanah berdasarkan SNI 8460:2017 menggunakan parameter nilai penetrasi standar (NSPT) rata-rata. Dalam analisis digunakan dua kondisi klasifikasi situs tanah yaitu soft soil dan medium soil. Klasifikasi situs tanah memiliki faktor amplifikasi untuk percepatan batuan dasar. Koefisien situs $\left(F_{P G A}\right)$ berdasarkan SNI 8640:2017 dapat dilihat pada Tabel 6.

Tabel 6. Koefisien Situs $F_{P G A}$

\begin{tabular}{ccccc}
\hline Bore Log & $\begin{array}{c}\text { Peta Gempa } \\
\text { Periode Ulang } \\
\text { [tahun] }\end{array}$ & $\begin{array}{c}\text { Kelas Situs } \\
\text { Tanah }\end{array}$ & $\begin{array}{c}\text { Fines Content } \\
{[\%]}\end{array}$ \\
\cline { 2 - 5 } 10 & 2002 & 500 & Soft Soil & 0 \\
\cline { 2 - 5 } & 2010 & 1.000 & Medium Soil & 15 \\
\cline { 2 - 5 } & 2017 & 2.500 & & 35 \\
\hline
\end{tabular}

(Sumber: Badan Standardisasi Nasional, 2017)

Perhitungan percepatan batuan dasar berdasarkan klasifikasi situs tanah dapat dilihat pada Persamaan 10.

$$
P G A_{M}=F_{P G A} \cdot P G A
$$

halmana:

$P G A_{M}=$ percepatan puncak yang disesuaikan dengan pengaruh klasifikasi situs, 
$F_{P G A}=$ koefisien situs,

$P G A=$ percepatan puncak batuan dasar.

Seluruh percepatan puncak yang disesuaikan dengan pengaruh klasifikasi situs tanah pada tiga peta gempa yaitu 2002, 2010, dan 2017 dengan klasifikasi situs tanah medium soil dan soft soil dengan periode ulang 500 tahun, 1.000 tahun dan 2.500 tahun dapat dilihat pada Tabel 7, Tabel 8 dan Tabel 9.

Tabel 7. Percepatan Puncak Periode Ulang 500 tahun

\begin{tabular}{cccc}
\hline $\begin{array}{c}\text { Klasifikasi } \\
\text { Situs }\end{array}$ & $\begin{array}{c}\text { Peta } \\
\mathbf{2 0 0 2}\end{array}$ & $\begin{array}{c}\text { Peta } \\
\mathbf{2 0 1 0}\end{array}$ & $\begin{array}{c}\text { Peta } \\
\mathbf{2 0 1 7}\end{array}$ \\
\hline Medium Soil & 0,23 & 0,25 & 0,28 \\
\hline Soft Soil & 0,3 & 0,33 & 0,34 \\
\hline
\end{tabular}

Tabel 8. Percepatan Puncak Periode Ulang 1.000 tahun

\begin{tabular}{cccc}
\hline $\begin{array}{c}\text { Klasifikasi } \\
\text { Situs }\end{array}$ & $\begin{array}{c}\text { Peta } \\
\mathbf{2 0 0 2}\end{array}$ & $\begin{array}{c}\text { Peta } \\
\mathbf{2 0 1 0}\end{array}$ & $\begin{array}{c}\text { Peta } \\
\mathbf{2 0 1 7}\end{array}$ \\
\hline Medium Soil & - & 0,33 & 0,36 \\
\hline Soft Soil & - & 0,36 & 0,36 \\
\hline
\end{tabular}

Tabel 9. Percepatan Puncak Periode Ulang 2.500 tahun

\begin{tabular}{cccc}
\hline $\begin{array}{c}\text { Klasifikasi } \\
\text { Situs }\end{array}$ & $\begin{array}{c}\text { Peta } \\
\mathbf{2 0 0 2}\end{array}$ & $\begin{array}{c}\text { Peta } \\
\mathbf{2 0 1 0}\end{array}$ & $\begin{array}{c}\text { Peta } \\
\mathbf{2 0 1 7}\end{array}$ \\
\hline Medium Soil & - & 0,36 & 0,44 \\
\hline Soft Soil & - & 0,36 & 0,36 \\
\hline
\end{tabular}

\subsection{Hasil Analisis Likuefaksi Variasi Peta Gempa}

Perhitungan analisis dilakukan dengan menggunakan variasi fines content (FC), yaitu fines content $0 \%$; $15 \%$; dan $35 \%$. Seluruh variasi analisis menggunakan tiga peta bahaya gempa, yaitu 2002, 2010, dan 2017 pada dua klasifikasi situs tanah, yaitu soft soil dan medium soil.

\section{Analisis Likuefaksi Fines Content $0 \%$}

Hasil analisis likuefaksi fines content $0 \%$ peta periode ulang 500 tahun. Berdasarkan hasil analisis pada Gambar 5. tanah dengan fines content $0 \%$ untuk peta gempa periode ulang 500 tahun, seluruh peta gempa terlikuefaksi. Kedalaman rata-rata terdalam hingga $19 \mathrm{~m}$ untuk analisis dengan peta gempa 2017. Kedalaman rata-rata likuefaksi terdangkal sedalam $16 \mathrm{~m}$ untuk analisis dengan peta gempa 2002.

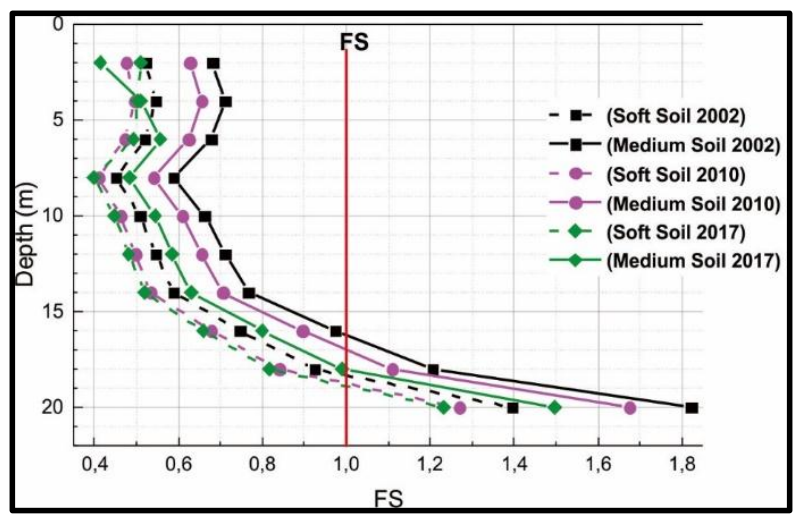

Gambar 5. Analisis likuefaksi fines content $0 \%$ peta periode ulang 500 tahun 
Menurut Day, R. W. (2001) likuefaksi terjadi hingga kedalaman $15 \mathrm{~m}$, dalam analisis menggunakan peta gempa 2017 periode ulang 500 tahun untuk soft soil dengan fines content $0 \%$ likuefaksi terjadi hingga rata-rata kedalaman $19 \mathrm{~m}$, hal tersebut disebabkan besarnya percepatan gempa yaitu $0,34 \mathrm{~g}$. Percepatan gempa sebesar $0,34 \mathrm{~g}$ menyebaban besarnya nilai Cyclic Stress Ratio (CSR) sehingga likuefaksi terjadi lebih dari $15 \mathrm{~m}$. Analisis menggunakan peta 2002 untuk kelas situs medium soil pada tanah fines content $0 \%$ likuefaksi terjadi hingga lebih $15 \mathrm{~m}$, hal tersebut terjadi akibat percepatan gempa lebih dari $0,1 \mathrm{~g}$. Percepatan gempa peta 2002 untuk kelas situs medium soil sebesar $0,23 \mathrm{~g}$. Selain percepatan gempa, ketahanan tanah terhadap beban gempa yang dipengaruhi oleh nilai fines content pada tanah. Tanah dengan fines content $0 \%$ sangat rentan akan terjadinya likuefaksi, nilai fines content yang kecil menyebabkan kecilnya nilai Cyclic Resistance Ratio (CRR), sehingga tanah tidak tahan terhadap gempa dan terlikuefaksi.

\section{Analisis Likuefaksi Fines Content $15 \%$}

Hasil analisis likuefaksi fines content $15 \%$ peta periode ulang 500 tahun. Berdasarkan hasil analisis pada Gambar 6. tanah dengan fines content $15 \%$ untuk peta gempa periode ulang 500 tahun, analisis dengan peta gempa 2002 dan 2010 untuk kelas situs medium soil likuefaksi hanya terjadi setebal tiga meter dan lima meter. Kedalaman rata-rata terdalaman likuefaksi hingga 16 m untuk analisis peta gempa 2017 dengan kelas situs soft soil.

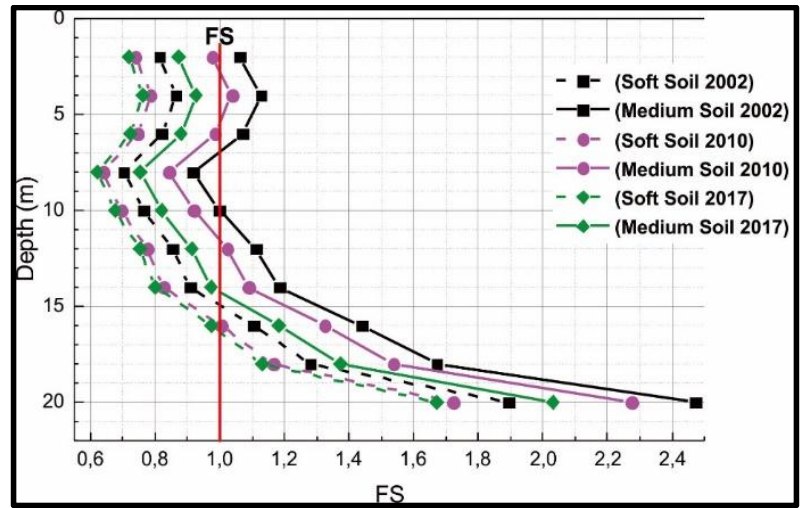

Gambar 6. Analisis likuefaksi fines content 15\% peta periode ulang 500 tahun

Percepatan gempa pada peta gempa 2002 untuk kelas situs medium soil sebesar 0,23g . Berdasarkan hasil analisis dengan peta 2002 untuk kelas situs medium soil, likuefaksi hanya terjadi setebal empat meter atau tidak terjadi pada seluruh kedalaman. Menurut Day, R. W. (2001) besar gempa minimal yang dapat menyebabkan likuefaksi sebesar 5 magnitude atau dengan percepatan gempa sebesar $0,1 \mathrm{~g}$. Pada analisis tanah dengan fines content $15 \%$ dengan percepatan gempa sebesar $0,23 \mathrm{~g}$ likuefaksi hanya terjadi setebal empat meter atau tidak terjadi pada seluruh kedalaman, hal tersebut disebabkan tanah dengan fines content 15\% memiliki nilai Cyclic Resistance Ratio (CRR) yang besar dan lebih tahan terhadap beban gempa atau gempa dengan percepatan $0,23 \mathrm{~g}$. Likuefaksi baru terjadi pada seluruh kedalaman hingga $15 \mathrm{~m}$ pada analisis menggunakan peta gempa 2017 untuk kelas situs medium soilatau dengan besar pecepatan gempa $0,28 g$.

\section{Analisis Likuefaksi Fines Content $35 \%$}

Hasil analisis likuefaksi fines content 35\% peta periode ulang 500 tahun. Berdasarkan hasil analisis pada Gambar 7. tanah dengan fines content $35 \%$ untuk peta gempa periode ulang 500 tahun, analisis dengan peta gempa 2017 untuk kelas situs medium soil likuefaksi hanya terjadi setebal tiga meter. Kedalaman rata-rata terdalaman likuefaksi hingga $15 \mathrm{~m}$ untuk analisis peta gempa 2017 dengan kelas situs soft soil. 


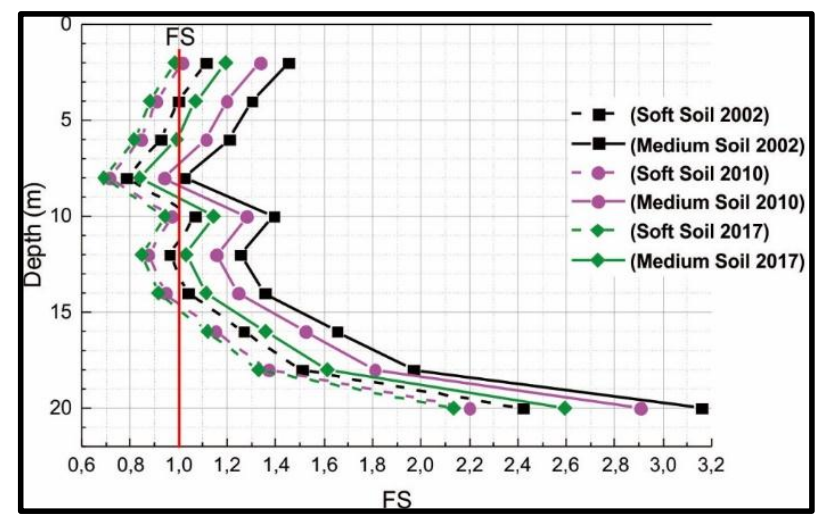

Gambar 7. Analisis likuefaksi fines content $15 \%$ peta periode ulang 500 tahun

Pada analisis tanah dengan fines content 35\% dengan percepatan gempa sebesar $0,28 \mathrm{~g}$ likuefaksi hanya terjadi setebal empat meter atau tidak terjadi pada seluruh kedalaman, hal tersebut disebabkan tanah dengan fines content 35\% memiliki nilai Cyclic Resistance Ratio (CRR) yang besar dan lebih tahan terhadap beban gempa atau gempa dengan percepatan $0,28 \mathrm{~g}$. Likuefaksi baru terjadi pada seluruh kedalaman hingga $15 \mathrm{~m}$ pada analisis menggunakan peta gempa 2010 dan 2017 untuk kelas situs soft soil atau dengan besar pecepatan gempa $0,33 \mathrm{~g}$ dan $0,34 \mathrm{~g}$. Analisis dengan kelas situs tanah medium soil hanya terlikuefaksi setebal empat meter, sedangkan untuk kelas situs tanah soft soil untuk ketiga peta gempa 2002, 2010, dan 2017 terjadi likuefaksi. Kelas situs soft soil memiliki percepatan puncak yang lebih besar sehingga terjadi likuefaksi hingga kedalaman $15 \mathrm{~m}$.

\section{KESIMPULAN}

Berikut adalah kesimpulan dari penelitian yang dilakukan:

1. Pada tanah dengan fines content $0 \%$ likuefaksi terjadi untuk analisis menggunakan peta gempa 2002, 2010, dan 2017.

2. Pada tanah dengan fines content $0 \%$ kedalaman rata-rata terdalam likuefaksi hingga 19 m untuk analisis menggunakan peta gempa 2017.

3. Analisis menggunakan peta 2002 dengan kelas situs medium soil pada tanah dengan fines content $15 \%$ tanah terlikuefaksi hanya setebal tiga meter.

4. Analisis menggunakan peta gempa 2010 dan 2017 terjadi likuefaksi pada seluruh variasi fines content $0 \%$, $15 \%$, dan $35 \%$.

5. Analisis dengan menggunakan peta gempa 2002 pada tanah dengan fines content $35 \%$ tidak terjadi likuefaksi.

6. Tanah dengan fines content $35 \%$ terlikuefaksi jika percepatan gempa lebih besar $0,33 \mathrm{~g}$.

7. Percepatan gempa untuk kelas situs soft soil lebih besar dari kelas situs medium soil.

\section{DAFTAR RUJUKAN}

Badan Standardisasi Nasional. (2017). SNI 8460:2017 tentang Persyaratan Perancangan Geoteknik. Jakarta: Badan Standardisasi Nasional.

Day, R. W. (2001). Geotechnical Earthquake Engineering Handbook. New York: McGraw-Hill Companies.

Ishihara, K. (1995). Earthquake Geotechnical Engineering. Rotterdam: CRC Press/Balkema.

Liao, S. S. C. \& Whitman, R. V. (1986). Overburden Correction Factors for SPT in Sand. Journal of Geotechnical Engineering, 112(3), 373-377.

Pusat Studi Gempa Nasional. (2017). Peta Sumber dan Bahaya Gempa Indonesia Tahun 2017. Bandung: Pusat Litbang Perumahan dan Permukiman - Kementerian PUPR. 
Seed, H. B. \& Idriss, I. M. (1971). Simplified Procedure for Evaluation Soil Liquefaction Potential. Journal of the Soil Mechanics and Foundations Division, 97(9), 1249-1273.

Seed, H. B., Tokimatsu, K., Harder, L. F. \& Chung, R. M. (1985). Influence of SPT Procedures in Soil Liquefaction Resistance Evaluation. Journal of Geotechnical Engineering, $111(12), 1452-1445$.

Youd T.L. \& Gilstrap, S.D. (1999). Liquefaction and Deformation of Silty and Fine-Grained Soils. The Second International Conference on Earthquake Engineering (pp. 1013-1020). Lisbon: A.A. Balkema. 